\title{
A fecundidade do inesperado
}

\author{
CATARINA NEVES
}

Título: Uma menina está perdida no seu século à procura do pai. Texto: a partir de um texto de Gonçalo M. Tavares. Encenação: Marco Paiva. Dramaturgia: Gonçalo M. Tavares, Marco Paiva. Interpretação: Ana Rosa Mendes, Andreia Farinha, António Coutinho, Carlos Jorge, Carolina Sousa Mendes, Filipe Madeira, Hugo Fernandes, Joana Honório, João Leon, João Pedro Conceição, Manuel Coelho, Nelson Moniz, Paula Mora, Ricardo Peres, Rui Fonseca, Tomás Almeida. Telões de cena: José Capela, António MV. Espaço sonoro: Hugo Franco. Desenho de luz e vídeo: Nuno Samora. Fotografia: Paulo Pimenta. Assistência de encenação: Maria de Lurdes Neto, Tiago Gonçalves, Júlia Luís. Produção: Crinabel Teatro. Co-produção: Teatro Nacional D. Maria II. Local e data de estreia: Teatro Nacional D. Maria II, 20 de Outubro de 2016.

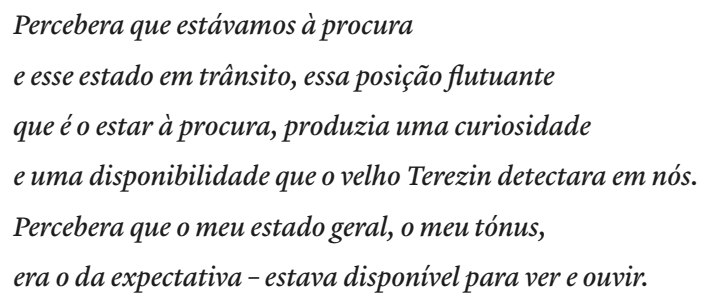

GONÇALO M. TAVARES, Uma menina está perdida no seu século à procura do pai

Impossível não reparar naqueles rostos, naqueles corpos. Alguns têm olhos rasgados, bochechas muito grandes, mãos muito pequenas, braços que parecem querer saltar do tronco numa dança sem coreografia. Sentados no sofá branco, de frente para o público, mostram-se na deficiência que não os arruma no ficheiro dos incapacitados. Têm o hábito mental de rejeitar a acção que remete para o não. Têm de o ter, para os encontrarmos, no seu século, à procura de trabalhar conceitos teatrais fora de formato, órfãos da palavra que nasce, para o mundo dos ouvintes, com a obrigação de ser bem dita. E chegam à Sala Garrett do Teatro Nacional D. Maria II, $o$ grande palco da cidade de Lisboa, perto do final do ano em que celebram trinta de paixão.

Ainda Portugal celebrava a força revolucionária dos cravos vermelhos e vivos e já um grupo de pais se barricava contra a ausência de 


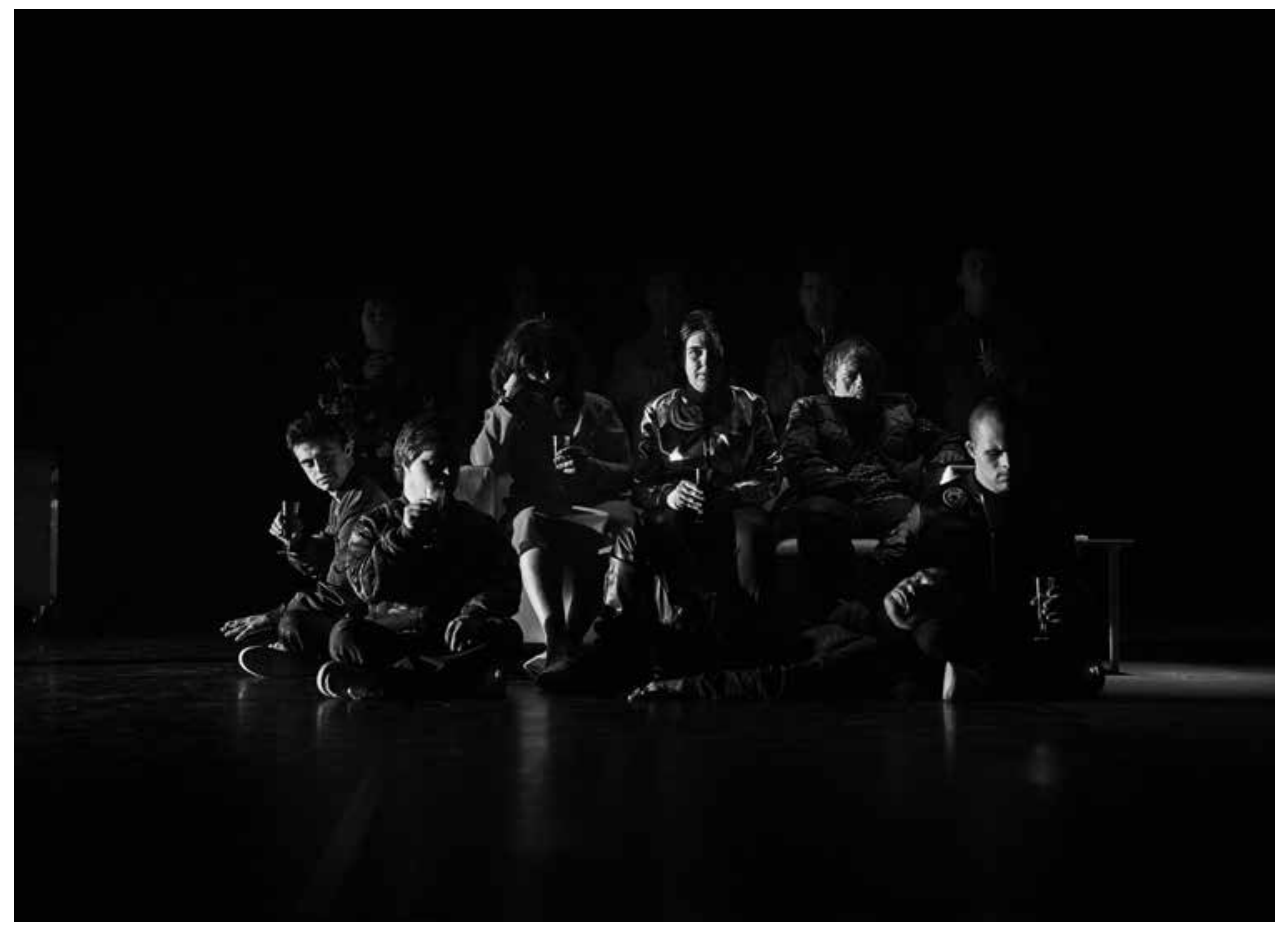

UMA MENINA ESTÁ PERDIDA NO SÉCULO À PROCURA DO SEU PAI, DE GONÇALO M. TAVARES, ENC. MARCO PAIVA, CRINABEL/TNDMII, 2016, [F] FILIPE FERREIRA

respostas para a inquietante pergunta: como caminhar com um filho que parece desencontrado, no tempo e no espaço?

Criar a Crinabel em 1975 foi como abrir uma janela de par em par. Onze anos depois, a cooperativa sem fins lucrativos ousou escancarar a porta, franqueando a entrada a quem diz com verdade a mentira imaginada. Hoje a Crinabel dá apoio a oitenta crianças e jovens com atraso no desenvolvimento. Tem sessenta e quatro funcionários e, desde 2005, acolhe no lar residencial dez pessoas com deficiência intelectual. E se o grupo de teatro da cooperativa começou, com o actor Francisco Braz, por levar à cena textos ligados ao programa de ensino, nos últimos dezasseis anos foi descobrindo outras construções estéticas, numa espécie de suave corte epistemológico. Era essa a vontade do actor Marco Paiva ao começar a dirigir o grupo de actores da Crinabel.

Uma menina está perdida no seu século à procura do pai é um título que faz o sumário da obra construída em volta da peregrinação de uma rapariga, com trissomia 21, numa Berlim trágica, numa contemporaneidade histórica, sem ano definido. A identificação óbvia e imediata - rapariga com trissomia 21 - entre a personagem e a actriz Carolina Sousa Mendes 
é apenas a excepção que confirma a regra, sendo aqui a regra o inverso de si mesma. O autor Gonçalo M. Tavares criou Hanna, 14 anos. Olhos: pretos. Cabelo: castanho. Embora perdida, Hanna encontra Marius. Procuram juntos. Na demanda do pai, cruzam-se com personagens insólitas numa viagem singular, na qual interessa mais o percurso que o ponto de chegada.

A peça de teatro parte do livro de Gonçalo M. Tavares para lhe dar outra forma. $\mathrm{O}$ autor confessou que essa transformação lhe traz alegria. O encenador garantiu, ainda durante o processo de criação do espectáculo, que, através do teatro, o livro passaria a ser outro objecto qualquer e que talvez a menina só andasse à procura de comunicar com alguém. Hanna apresenta-se: «Hanna, catorze anos, 12 de Outubro, olhos pretos, cabelo castanho.» Um dos actores anuncia o começo do espectáculo. Fala o fotógrafo/torturador de animais, admira os que antecipam catástrofes como as ratazanas e os que se reproduzem aos milhares enquanto os homens fazem as guerras, como o escaravelho. Ocupa-se ainda de fotografar deficientes. Não num cartaz, mas numa projecção, a frase «a vibração da paisagem não impedirá a vida» desperta as mentes para a luta que acabará por se fazer e lança-nos na cena seguinte.

A família que cola cartazes pelo mundo anuncia, através de um dos irmãos, Fried Stamm, interpretado pela actriz do TNDMII Paula Mora, que pretende «instalar alguma confusão», «avisar as pessoas», embora não queira «provocar uma revolução». Vestida com um macacão de ganga, Paula Mora assume um tom expressivo, por vezes mimetizando a criança que alegremente conta a traquinice que gosta de fazer com os amigos. Será a personificação da utopia numa unidade universal de ideias e acção?

Nesta história que a História vai engolindo, há um hotel onde cada quarto tem o nome de um campo de concentração. E aqui aparecem caixas. Pela primeira vez faz sentido, neste espectáculo, a imagem da caixa onde se enfiam pessoas e medos. São tantas quantos os campos de concentração e desenham um percurso num telão, que, ao descer, parece esmagar as personagens, como se as agrilhoasse.

Marius quer ajuda para decifrar mais uma pista sobre o paradeiro do pai de Hanna: um colar antigo. Tenta a sorte junto de um antiquário fascinado com um relógio cujo mecanismo funciona, mas os ponteiros estão estragados. Marius e Hanna terão de esperar. Talvez daí a uns dias se consiga chegar a alguma certeza. $\mathrm{O}$ assunto requer investigação. 


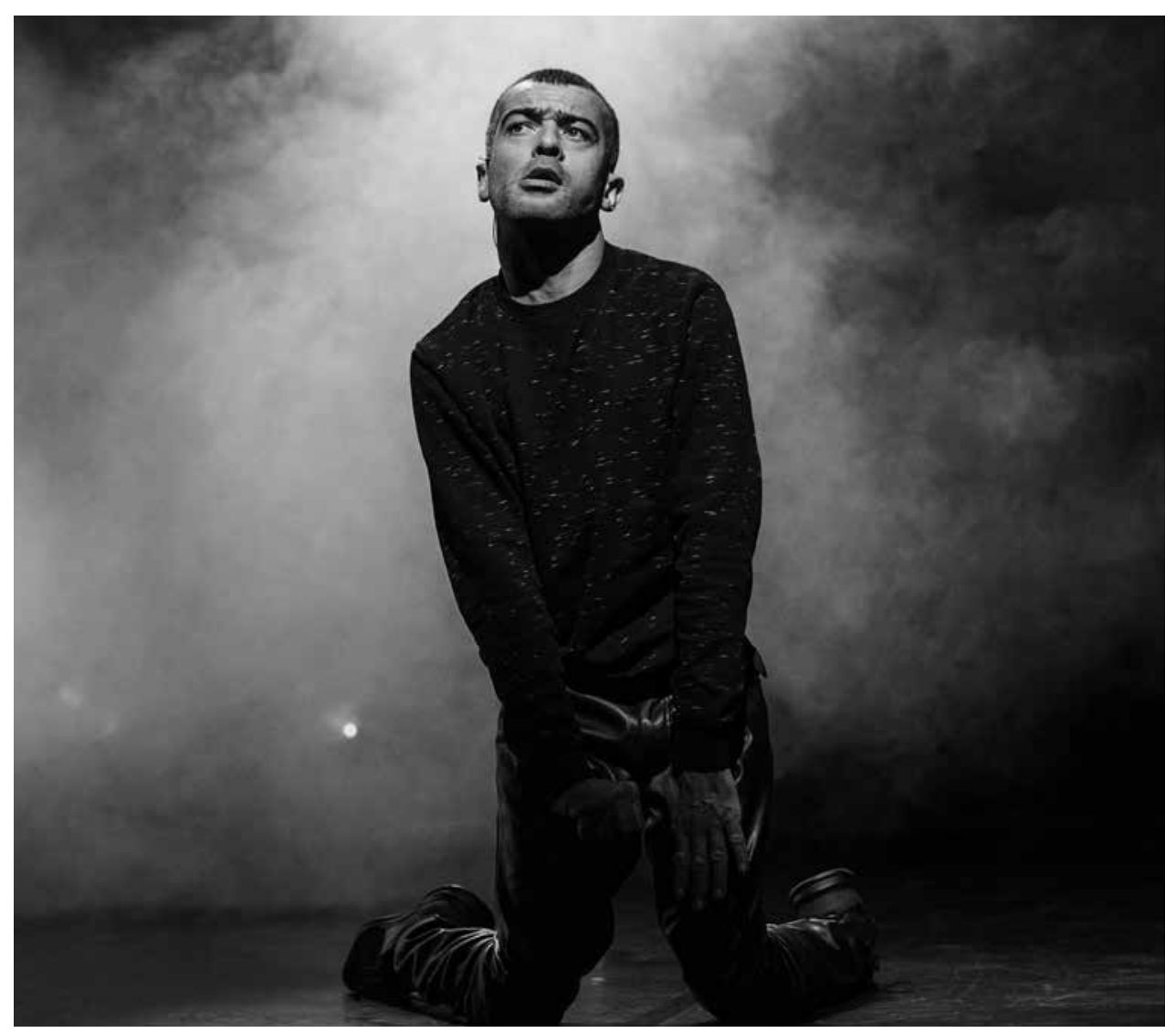

UMA MENINA ESTÁ PERDIDA NO SÉCULO À PROCURA DO SEU PAI, DE GONÇALO M. TAVARES, ENC. MARCO PAIVA, CRINABEL/TNDMII, 2016 (NELSON MONIZ), [F] FILIPE FERREIRA

Mesmo quando o homem é forçado a não contar as horas, o tempo vai cavando o buraco de onde só sairá se e quando alguém disser não. Diz o antiquário: «isto é uma corrida de resistência. Trata-se de resistir.» Como o fez o dono do hotel. Mesmo quando ficam as marcas.

Num dos momentos mais fortes do espectáculo, apesar de o volume da música poder perturbar a percepção da acção verbal, Manuel Coelho, um dos dois actores da companhia do TNDMII que participa neste trabalho, despe a camisa e vira-se. A palavra judeu é projectada nas costas do actor. Em português e em várias outras línguas. «Nem depois de morrer isto vai sair...», diz o dono do hotel. Por cima, durante toda a cena, como se fosse uma legenda, a frase: «mudar os hábitos mentais».

$O$ segundo momento retumbante vem logo a seguir. O Velho Terezin entra. Vai à boca de cena. Está sozinho. Faz contas ao peso das coisas. Conclui: «o peso das minhas coisas deve ser menos de metade do peso do 
meu corpo. Quanto menos peso tivermos à volta do corpo, mais rápido fugiremos, mais forte será o nosso instinto de sobrevivência.» $\mathrm{O}$ actor Nelson Moniz terá sempre dificuldades físicas para fugir rapidamente. O corpo será, por vezes, um peso que o impede até de se pôr de pé sem ajuda. Com os instrumentos básicos de representação limitados, Nelson Moniz usa com perícia o corpo rebelde, com ritmo a voz codificada e com inquietação o movimento domesticado à força. Se o teatro existe também para criar ressonâncias, aqui cumpre o papel, sem espaço para condolências. Damos por nós, que estamos sentados na plateia, do bem possível incómodo inicial ao estado encantado do deslumbramento.

A plácida correria de personagens carregadas de aberrações chega à meta quando Marius e Hanna têm de fugir. Marius envolveu-se numa zanga demasiado violenta com o fotógrafo. Agora, Marius e Hanna são como aqueles atletas que correm distâncias curtas e por milésimos de segundos celebram ou frustram. $\mathrm{O}$ amigo de Marius que lhes dá guarida colecciona horas e horas de gravações de corridas de cem metros.

Apesar das dificuldades técnicas, no dia da estreia, na projecção dessas imagens acompanhadas do som dos comentadores, fica claro o efeito pretendido: sublinhar a repetição da procura na certeza de que, como escreveu o filósofo francês Pierre-Joseph Proudhon, «nascemos perfectíveis, mas nunca seremos perfeitos».

Assistir a um espectáculo da Crinabel Teatro é como ver um conjunto de músicos a improvisar a partir do que está estudado e apreendido. Sabemos que cada representação é irrepetível não apenas porque essa é a condição do teatro, mas porque estes actores, ao serem mais sangue e nervos do que intelecto, obrigam o espectador a descobrir outras formas de ver e ouvir. Eles estão na vida com uma liberdade invejável. E nós?

Habituado a trabalhar com actores não profissionais, sem-abrigo e deficientes, o actor, encenador, dramaturgo e realizador italiano Pippo Delbono afirmou há pouco tempo, em declarações a um jornal: «A verdade não é o naturalismo. É de lucidez que precisamos, não de naturalismo. Porque é a arte que revela a verdade.»

A verdade em Uma menina está perdida no seu século à procura do pai encontra-se na intuição dos actores, no cuidado posto nas luzes criadoras de uma atmosfera por vezes intimista, outras asfixiante, e encontra-se no espaço sonoro que quase sempre existe além da história, mas em sintonia com ela.

Amanhã, a cortina de tule que separa o palco da plateia vai voltar a embaciar a vista, mesmo, mesmo antes de começar apesar de já ter 
começado. A luz amarela vai aquecer o sofá branco que preenche o palco quase nu da Sala Garrett do TNDMII. Os actores vão ter um copo na mão e vão estar sentados no sofá branco. Vão voltar a olhar-nos de frente. São os mesmos que eu vi, num dos primeiros ensaios de Uma menina está perdida no seu século à procura do pai, à procura, no chão e sem esforço, do encaixe perfeito uns nos outros e deles com o público. Conseguiram. Fica a vontade de descobrir mais peças de um puzzle tão novo quanto velhos são os nossos preconceitos. Sem eles, é mais fácil perceber e aceitar a «fecundidade do inesperado». 